\title{
Accreditation/Certification for Adult ESL Instructors in Canada: An Overview
}

\section{Diane Keevil Harrold}

\section{Introduction}

The question of whether to pursue accreditation of noncredit adult ESL instructors was placed on the agenda of TESL Nova Scotia in mid-1994. TESL Nova Scotia determined to research the accreditation experience of other provincial ESL organizations in Canada: the process, the achievements, and the results. The research for the project began in November 1994, and the final report, Accreditation/Certification for Adult ESL Instructors in Canada: An Overview, was presented to TESL Nova Scotia on February 7, 1995. The report first identifies, compares, and contrasts what has been done in British Columbia and Alberta where certification/accreditation protocols have been in place for several years (the first section). Second, the ongoing processes toward accreditation/certification in Saskatchewan, Manitoba, and Ontario are outlined. In April 1995, as a result of a membership poll, TESL Nova Scotia chose to pursue accreditation.

\section{A Comparison and Contrast of Certification in $\mathrm{BC}$ and of Accreditation in Alberta}

The British Columbia professional certification levels and the Alberta minimum standard for accreditation have been in place since 1992. Because the goals, processes, and protocols in BC and Alberta differ in a number of significant aspects, comparison and contrast of the two, and of the results they have obtained, will be informative with regard to accreditation in other jurisdictions and with regard to the decision as to whether and how to proceed.

\section{What Were the Rationale and Goals for Certification/Accreditation?}

\section{British Columbia}

Why Was Certification Pursued?

The issue of the absence of professional standards for instructors had become more pressing with the rapidly expanding number of private ESL schools in British Columbia in the 1980s. The Association of BC Teachers of English as Another Language (BC TEAL) began to research this issue in the early 1980s.

\section{Alberta}

Why Was Certification Pursued?

The accreditation process was begun by Alberta Teachers of English as a Second Language (ATESL) in part because of the absence of professional standards for ESL instructors in the context of a proliferation of new ESL programs receiving LINC funding. 


\section{Rationale and Goals}

"By gaining experience within the framework of a professional institution and through ongoing commitment to professional development, ESL instructors strive to enhance knowledge and abilities, and to add to the field of ESL." (Instructional Qualifications, Chapter 4, Recommended Standards for British Columbia ESL Institutions, TEAL Institutional Standards Advisory Committee).

TEAL goals for instructors and instruction include the following:

- to articulate standards

- to help ensure that students are protected from exploitation

- to promote the teaching of ESL as an academic discipline and a valued profession

- to improve ESL instruction and ensure basic instructor qualifications

- to encourage improvement of preparation and training of professionals in the field of ESL (Adapted from Goals of the TEAL Standards, Chapter 1, Recommended Standards for British Columbia ESL Institutions, TEAL)

\section{Definition: to Certify or Accredit? \\ $\mathrm{BC}$ chose certification.}

The essential requirements of a profession were defined as:

- selective entry

- mandatory training that includes a balance between theory and practice

- social responsibility, nationally and internationally (TEAL Professional Standards Committee Report, February, 1987)

The term certification, chosen by BC TEAL, reflected the goal of articulating, from the beginning, a high standard to define ESL professionalism, and of encouraging professionals to enhance their knowledge and abilities. The standards would also encourage ESL teacher training institutions to improve the training and preparation of ESL professionals. These goals had a profound effect on the process and outcome of TEAL certification.

\section{Rationale and Goals}

"Accreditation allows us to take control of our own professional stàndards, to identify and to bind ourselves as a cohesive group. Taking a stand on minimum requirements for ESL teachers sends a message to employers and funders that we are prepared to back our claim to professional status with action. The need for accreditation is also based on the belief that only qualified TESL professionals can bring that necessary skills to articulate questions and solutions to issues in the field." (Section 1.0, Accreditation of ESL Teachers in Alberta, ATESL, October 24, 1992)

Public Awareness: "A more precise definition of who ATESL represents allows us to lobby more effectively for stable funding from both the provincial and federal governments."

Student's right to Qualified Instruction: "Accreditation defines a minimum combination of specialized education and classroom experience to ensure this."

Teaching Quality/Access to Training: "Accreditation is part of the search for excellence regardless of the recognition or status it brings ... ATESL's standards will help to highlight areas of limited choice in ESL related course work." (Section 2.0, Accreditation of ESL Teachers in Alberta, ATESL, Oct. 24, 1992)

\section{Definition: to Certify or Accredit?}

Alberta chose accreditation.

Alberta did not endorse the certification model and the assumptions implied in it:

"There is a difference between certification and accreditation. The former is a 'hard line' approach which may include any of the following features: clearly established (high) standards for education and experience, standardized competency exams, exclusive right to title and practice, a code of ethics and disciplinary procedures. The latter is a broader, more flexible process which validates or confirms the credentials of an individual." (Section 1.3, Accreditation of ESL Teachers in Alberta Committee Brief, November, 1991)

ATESL indicated, in their rationale and their choice of definition, the desire to bind themselves into a strong pressure group as a precursor to changing and improving the status of the profession, and the effectiveness. 
In keeping with this intention, a tiered system of levels above minimum was proposed to recognize and encourage further achievement in the areas of experience, education and professional involvement.

\section{Committee or Consensus?}

Certification requirements would be a definition of professional standards for ESL teachers that would be articulated by the professional institution, TEAL. A TEAL committee in consultation with universities, community colleges and private language institutions would set the standards. In 19861987, the Ministry of Education and the BC Teachers' Federation were also consulted. This process choice reflects the goal of articulating or setting standards to enhance and add to the field of ESL.

\section{Should an Inclusive Model be Pursued?}

The TEAL committee decided that certification would only be granted to individuals with specific ESL professional training. It would not be granted to teachers or volunteers with experience but without training. (Credit for some volunteer experience is given in Level Two Certification.)

The TEAL model did not set out to be an inclusive model or to recognize the status quo by accommodating as many ESL teachers and training programs as possible.

\section{Credit or Noncredit ESL?}

At first, TEAL considered developing a certification system that would include both credit (K-12) and noncredit adult ESL instructors but decided to set certification standards specifically for adult ESL noncredit, where uniform standards did not exist.

Combined certification of credit ESL with noncredit adult ESL has not yet been pursued successfully in any jurisdiction in Canada. of training programs. The intention to initially confirm the credentials and validity of as many Alberta ESL teachers as possible follows from the rationale and definition.

In the interests of unity and strong professional identity, ATESL would have a single nontiered minimum standard for qualified ESL professionals.

\section{Committee or Consensus?}

"Our intention is not to arbitrarily set standards. Rather we feel that a consensus arising from the membership is the only way that we, as a profession, can define standards by which we measure ourselves ... ATESL standards will define the minimum but essential characteristics of an ESL teachers." (ATESL Newsletter, September, 1988)

Therefore, ATESL chose a consensus model for both the process and the ratification of the resulting protocol.

\section{Should an Inclusive Model be Pursued?}

ATESL decided to provide the opportunity for accreditation to teachers with ESL experience but no specific ESL training and, therefore, to give credit and peer recognition to much of the existing ESL community, including volunteers. This was in compliance with their goal of developing strong professional identity and unity.

An eventual minimum standard would ensure professionalism: "ATESL reserves the prerogative to establish minimum standards which may, after a certain 'grace' period be the only option available." (Accreditation of ESL Teachers in Alberta, October 24, 1992) 


\section{Conclusion}

Many similarities can be seen between TEAL and ATESL in the rationale and goals for certification/accreditation. For example, both sought to establish standards for ESL instructors. Both wished to improve the quality and accessibility of ESL teacher education and professional development opportunities, and to protect a student's right to qualified instruction. Both would establish standards independent of government recognition.

Although both aimed for professional recognition from funders, from government, and from employers, ATESL stated specifically that it would establish standards in preparation for pressuring governments for program improvements.

However, significant differences also arise from the rationale and goals for the standards. ATESL had the intention of establishing unity within the ranks of ESL teachers and of initially recognizing existing teacher credentials and teacher training programs. In process, these intentions became translated into 'identifying' standards based on the membership's stated priorities, using a consensus approach.

TEAL, on the other hand, had the goal of setting entry level standards requiring specific kinds of ESL training to encourage instructors and training programs to meet these standards of professionalism. The process that TEAL used to satisfy its goals was that the standard would be articulated by a professional TEAL committee in consultation with a cross-section of ESL instructor training and employing institutions.

Establishing goals and a definition that clearly reflect the intention of the professional organization or community would appear to be the definitive step in establishing professional standards, because the seeds of the process and product are contained within.

\section{What Was the Process for Achieving Certification/ Accreditation?}

\section{British Columbia}

Process

Time Required for Process

1985 Professional Standards Committee established

1992 Certificates with existing qualifications began to be granted.

1. 1971 Graduates from a UBC ESL course were given TEAL certification. This process was eventually suspended.

2. 1985 A TEAL Professional Standards Committee was appointed and met to research existing standards and make recommendations:

\section{Alberta}

Process

Time Required for Process

- 1988 Process initiated

1992 Certificates with existing qualifications began to be granted.

1. 1988 A report setting out the rationale for pursuing accreditation and the goals of the ATESL Working Committee on Accreditation was published in the September ATESL newsletter:

it is clear that ESL teachers can be defined along many dimensions. We have identified three major areas: (a) training, (b) experience, and (c) professionalism. Polling our membership on specific details under 
- 1986-1987 The Committee recommended a tiered system of three certification levels and began to consult with universities, community colleges, the Ministry of Education and the BC Teachers' Federation

- 1987 A detailed description of the three certification levels was presented and was approved by the executive. The levels included Level I (entry level), Level II (certificate), Level III (Advanced)

- These certification levels were presented for discussion at the Annual General Meeting in March 1987.

- These first standards for Level One Certification required ESL methodology at the university level, a practicum or experience in teaching, and demonstrated participation in cross-cultural environments, settings.

- 1988 the first applicants for certification came to the committee

3. 1988 The TEAL Professional Standards Board was appointed. It represented a cross-section of the ESL teacher training and employing institutions and included members from: the TEAL executive; University of Victoria, Simon Fraser University (SFU) and the University of British Columbia (UBC); community colleges; and private international schools.

- 1991 Vancouver Community College (VCC) developed an instructor education program for ESL. This was a new certificate program specifically for training adult noncredit ESL teachers. This program requested inclusion for TEAL certification. Because it was not university-based it did not fit the certificate requirements.

- 1991-1992 Certification was suspended for 18 months. Acceptance of nonuniversity teacher training programs was a major area of discussion in the process for over a year and signalled a significant change in the certification standards that originally accepted only university ESL teacher training. these headings will result in the minimum but essential characteristics of an ESL teacher. (ATESL Newsletter, September 88)

- A consensus building approach was decided on. Every step of the process was described in the ATESL newsletter. Only ATESL members could take part in the process.

- 1988 Twenty-nine employers of ESL instructors were polled. All agreed that ESL required specialized training and/or experience. The vast majority were in favor of the principle of accreditation. Two thirds felt it would have an impact on their hiring practices. All agreed that some kind of practicum as part of training was important either at university or college level to attach more credibility to the accreditation.

2. 1988 All people attending the ATESL Conference attended a panel discussion on accreditation and filled out a questionnaire to allow ATESL to determine the direction the accreditation process would take:

- 31 questions were used to determine attitudes by asking participants to rank the importance of various training and education subjects and courses, of different kinds of teaching experience, of professional membership and involvement.

- Attitudes toward accreditation and opinions on how to measure and assess teaching experience were also gathered, as well as personal information about the experience and training of the person filling out the form.

3. 1989-1991 The ATESL Working Committee on Accreditation fashioned draft options based on the questionnaire findings. The drafts were presented at public meetings of ATESL members and put in the newsletter to ensure that all members would be informed and would have the opportunity to attend. The meetings occurred over a year.

Then the ATESL Working Committee on Accreditation developed the requirements for accreditation based on the questionnaire and the consultations, and put forth the options for accreditation: 
4. 1992 The Vancouver Community College program was accepted for TEAL certification, changes were made to the requirements, and the levels and criteria that now exist were adopted:

- 100 hours of TESL training is required that may be from either a university or a recognized teacher training program outside the university context

- the requirements for a university TESL methodology course was changed to an "approved TESL methodology course"

- the practicum requirements also changed to require a specific supervised TESL practicum. ESL courses in Education at SFU do not meet this requirement

- those who had been certified in 1988-1990 were grandfathered into the new levels.

\section{The University vs. Non-University}

\section{ESL Teacher Training Issue}

There was a lack of agreement in the committee about whether nonuniversity training should be accepted for certification.

According to Kelleen Toohey, Associate

Professor of Education, SFU, objections were related to the fact that recognition of ESL as a discipline is difficult enough even when teacher training has the influence and reputation of a university to back it. Retaining ESL teacher education in the university setting would enhance credibility and recognition for the profession.

This introduces the difficult and often divisive issue of whether training for adult noncredit ESL is best handled in current courses offered in faculties of education. The new Vancouver Community College program, for example, had a rigorously monitored practicum specifically for adult ESL, something that university education programs with their emphasis on training K-12 teachers do not always have. ESL practicum courses in Education at SFU do not meet TEAL requirements.
- Option A or the eventual minimum requirement was stated in 1989;

- Options B and C and the administrative guidelines for accreditation were stated in 1989-1990;

- The proposed Options for accreditation and the administrative guidelines were presented once again in public forums.

4. 1991 A referendum ballot was sent to all ATESL members. Of 275 ballots, approximately half were returned; $89 \%$ of those returned were in favor of a voluntary single-tiered endorsement process; $81 \%$ were in favor of the standards and administration proposal outlined by ATESL ( $A c$ creditation of ESL Teachers in Alberta Committee Brief, November, 1991)

In November 1991, the committee released a brief of all that had been decided, $A C^{-}$ creditation of ESL Teachers in Alberta, published in October 1992, was virtually unchanged in essence from the $1991 \mathrm{com}-$ mittee brief. The ATESL accreditation process was instituted.

\section{The University vs. Non-University ESL Teacher Training Issue}

(See Teaching Qualifications and the Practicum in the first section.)

ATESL accepts postgraduate training directly related to teaching second languages, whether it be a diploma, certificate or a master's degree, as long as that training includes a minimum of 250 hours of instruction, and as long as the individual has a university degree in addition.

ATESL has not stipulated specific contents of postgraduate second language teacher training and thus has avoided, or perhaps postponed, this potentially divisive issue. 
Related issues were also at the root of the breakdown of the certification process in Manitoba (see second section, Manitoba).

\section{Conclusion}

The ATESL consensus process, which included many consultations with the membership and opportunities to affect the process, eliminated major divisions within ATESL because the results were so clearly the wishes of the majority of the constituents. Employing a consensus process, in which the standards evolved from the professional organization's membership, may have ameliorated the rift over certification qualifications that is unresolved in $\mathrm{BC}$.

Even though a consensus process must inevitably compromise the standards of some of the participants, the eventual minimum standards in BC and Alberta are comparable in requirements, as becomes clear in the following section.

The membership in Alberta chose to recognize experienced teachers without specific training, which initially diluted the minimum standard. Not all ATESL members agreed, but they accepted the wishes of the majority. $\mathrm{BC}$, on the other hand, because of a nonconsensual approach, was able to insist on an undiluted high minimum standard from the beginning.

\section{What Standards Resulted?}

\section{BC TEAL Professional Certificate Levels}

Not applicable.

ATESL Minimum Standard for Accreditation of ESL Teachers

Option C (Expired)

University Degree: Not Applicable

Option $C$ recognized the contribution of volunteers and of experienced teachers with no specialized education.

Postgraduate Work: Not Applicable

Classroom hours: 1220 hours of documented classroom time in which (a) the candidate is employed as a teacher; and (b) the language of instruction is predominantly English.

Total Required Credit Hours: 1220 hours ATESL membership is a requirement. Available only for the first year of accreditation, Option $C$ is a permanent accreditation (provided ATESL membership is maintained). 
Not applicable.

\section{TEAL Professional Certificate:}

\section{Level One (Entry Level)}

To be eligible the applicant must:

1. have an undergraduate degree from an accredited university, or a three year teacher training certificate from a recognized/accredited teacher's college;

2. have a minimum of 100 hours of TESL training including both theory and supervised practicum from:

a. an accredited university

b. a recognized teacher training program

3. Submit a TESL practicum/observation report and a personal reference letter.

The TEAL Professional Certificate: Level One will expire in five years.

- There will be no renewal of the Level One certificate except under special circumstances.*

- At the end of five years, individuals will be expected to upgrade to a TEAL Professional Certificate Level Two.

- Special circumstances that would be considered include years out of the profession for reasons such as temporary career change and childrearing. In this case, the individual would need to make a special application for permission in the form of a letter written to the Professional Standards Advisory Board.
Option B (Expires 1997)

University Degree: 700 hours in any academic field.

Postgraduate Work: Not Applicable

This option recognizes that some experienced ESL teachers do not have specialized ESL education.

Classroom hours: 520 hours of documented classroom time in which (a) the candidate is employed as a teacher; and (b) the language of instruction is predominantly English.

Total Required Credit Hours: 1220 hours. ATESL membership is a requirement.

Available for five years, Option B expires in 1997. Option B is a permanent accreditation (provided ATESL membership is maintained).

\section{Entry Level Option (Approved)}

Interim accreditation for TESL graduates who meet the minimum standard for education but lack experience has been approved but not detailed. (Source: Veronica Baig, ATESL Accreditation Board). 
TEAL Professional Certificate:

\section{Level Two}

To be eligible, the applicant must:

1. Have an undergraduate university degree;

2. Meet all the TEAL Professional Certificate: Level One criteria.

Note: Applicants must provide all the documentation required for the TEAL Professional Certificate: Level One with their application.

3. Present a documented record of successful teaching. This must include:

a. two practicum or observation or teaching reports by supervisors or peers;

b. two letters of reference or two reference forms

4. Have a minimum of 600 hours of full-time classroom teaching. All classroom teaching must be documented with institutional records or institutional contracts.

Note: A minimum of 300 hours over a period of three years is required for individuals teaching part-time. Teaching part-time is defined as teaching less than seven hours a week.

5. Have attended or participated in professional development over and above preservice TESL training. Examples include: materials development; curriculum or program development; written publications; presenting workshops or participating in presentations; attending courses, workshops, or presentations (university courses, TESL professional development courses or workshops, summer institutes, conferences).

Level Two is the minimum permanent certification level that all applicants must attain after a five-year period of grace.

\section{Option A-The Minimum Standard (1997)}

University Degree: 700 hours in any academic field.

Postgraduate Work: 250 hours minimum in a specialization directly related to the field of TESL. This postgraduate work may be a diploma, a certificate, or a master's degree. Classroom hours: 250 hours of documented classroom time in which (a) the candidate is employed as a teacher; and (b) the language of instruction is predominantly English.

Total Required Credit Hours: 1220 hours

ATESL membership is a requirement.

Beginning in 1997, Option A will be the only option available for new applicants.

(From Accreditation of ESL Teachers in Alberta, 1992, and Accreditation of ESL Teachers in Alberta Committee Brief, 1991) 
Level Three (Advanced Level)

To be eligible, the applicant must:

1. Meet all the TEAL Professional Certificate: Level Two criteria;

Note: Applicants must provide all the documentation required for the TEAL Professional Certificate: Level Two with their application.

2. Have five years of full-time classroom teaching and/or ESL/EFL program supervision with a minimum of 600 hours of classroom teaching or program supervision in each of the five years. Three of the five years must be in the area of ESL/EFL classroom teaching. All teaching experience and program supervision must be documented with official institutional records or contracts.

3. Have additional graduate or undergraduate course work in TESL and related fields over and above and subsequent to the pre-service TESL training. Criteria for acceptable coursework include:

a. coursework must be equivalent to a fulltime year at university (e.g., UBC: five 70-hour courses);

b. Graduate and undergraduate level courses in TESL beyond pre-service TESL training;

c. course work from acceptable related fields of study including linguistics, cross-cultural counselling, multicultural studies, adult education, and study in an additional language such as French, Japanese, etc.

4. Have made contributions to the field of ESL/EFL instruction. Examples: serving and contributing to the work of professional committee(s) or association(s); sponsoring student teachers, or working with international teachers of English; giving professional presentations at conference(s) or to colleagues at local educational institutions. 
TEAL Professional Certificate:

Level Four (Master Teaching Level)

To be eligible, the applicant must:

1. Meet all the TEAL Professional Certificate: Level Three criteria;

Note: Applicants must submit all the documentation required for the TEAL Professional Certificate: Level Three with their application.

2. Have a master's degree in TESL or in a related field of study.

3. Have a minimum of eight years of fulltime classroom teaching and/or ESL/EFL program supervision with a minimum of 600 contact hours in each of the eight years. Three of the eight years must be in the area of ESL/EFL classroom teaching. All teaching experience and program supervision must be documented with official institutional records and contracts.

(From Standards for Professional Certification, BC TEAL Professional Certification Service, 1994).

\section{A Comparison and Contrast of the Standards}

\section{Professional Development and \\ Membership Requirements \\ British Columbia}

Membership in TEAL is not a requirement. $B C$ requires evidence of involvement in professional development to gain permanent minimum certification (Level Two). Rigorous evidence of professional development is also required to gain advanced levels of certification. This is consistent with TEAL's intention to foster ongoing commitment to professional development. However, no provision is made to ensure that professional development and involvement continue once a permanent certification level is gained.
Not Applicable

\section{Professional Development and}

Membership Requirements

\section{Alberta}

ATESL membership is a requirement for accreditation and for maintaining accreditation status. This is consistent with the ATESL goal to strengthen ATESL to effect changes. No other professional development requirements are made. However, membership in a professional organization is considered an important indicator of professionalism and is an indicator of ongoing professional development and involvement. 
Minimum Education and Experience Requirements for Permanent

\section{Recognition}

An undergraduate university degree, 100 hours of TESL training, and 300-600 hours of teaching experience is the minimum requirement for permanent TEAL certification (Level Two).

TEAL requires more hours of teaching experience and fewer hours of TESL training than ATESL, but is more specific about the kind of TESL training required.

The quantity of education and experience required is roughly equivalent.

\section{Evaluation of Teaching Experience}

Teaching hours refer to contact hours only.

A "successful" teaching record is documented by either supervisors or peers. This represents an effort to determine the effectiveness of a teacher. (A requirement to have reports from both peers and supervisors, if possible, would present the most balanced evaluation.)

\section{Grandfathering: Temporary Credit for Experience in ESL Without Required Training}

In accordance with the TEAL goal to promote ESL teaching as an academic discipline and a valued profession, rigorous training, experience, and professional involvement standards were set to signal to employers that TEAL certification represents a professional community.

Teaching experience without training is not and has not been accepted for certification. A maximum of 100 hours of volunteer experience is accepted for Level Two if it is supervised and if the supervisor writes a reference. A reference or institutional record or contract is required from each institution.

\section{Minimum Education and}

Experience Requirements for Permanent Recognition

A university degree, 250 hours of postgraduate TESL training, and 250 hours classroom experience will be the minimum requirement for permanent ATESL accreditation in 1997 (Option A).

ATESL requires more hours of TESL training than TEAL, but is less specific about the kind of training and requires fewer hours of classroom experience.

The quantity of education and experience required is roughly equivalent.

\section{Evaluation of Teaching Experience}

Classroom hours refer to contact hours with a class, but a class does not include a tutoring situation.

Contact names are asked for, but the word of the teacher is accepted regarding experience, and letters attesting to effectiveness are not required. Observations are not required. Other than requesting contact names, Alberta has made no effort to document the effectiveness or success of an instructor, relying perhaps on a longer required period of teacher training.

\section{Grandfathering: Temporary Credit for Experience in ESL Without Required Training}

ATESL, in accordance with its goal to present a united front to funders and employers, chose to give the opportunity to gain accreditation to as wide a variety of experienced ESL teachers as possible. The eventual minimum standard for accreditation would be implemented or grandfathered in stages.

The ATESL board resolved on September 23, 1989, "That entry level standards for accreditation for ESL teachers in Alberta start with a series of equivalent standards." 1220 hours credit is required for accreditation and one hour of university education was considered roughly equal to one hour of classroom experience. ATESL members disagreed on whether experience or training was more important and the consensus was that they were both important. 
Grandfathering is a source of controversy in the TESL profession in Canada. Those against it do not believe that individuals should grandparent into a profession and that doing so dilutes the effect of standards for the first generation of teachers recognized.

The proportion of adult ESL teachers who have gained TEAL certification is relatively small, in part because of the decision to set high standards from the onset with no grandfathering. TEAL is working very effectively with ESL providers, both public and private, to have TEAL institutional standards adopted. Many more experienced teachers may need to reach TEAL requirements eventually. (For more detail, see below "What Has Been the Outcome?" and "What is the Next Step?)

\section{Teaching Qualifications and the Practicum}

TESL training must be 100 hours including a "supervised practicum." A TESL practicum report must be included.

The definition of a supervised practicum is:

- A standardized set of criteria are used by the student teacher, the sponsoring teacher, and the practicum supervisor.

- A minimum of 20 hours are spent by the student teacher in the classroom.

- The sponsoring teacher is selected by the ESL teaching training program.

- The sponsoring teacher writes a report on all 20 hours of the practicum.

- A practicum supervisor from the ESL teacher training program observes the student teacher teaching for at least one hour, followed by at least a half-hour conference with the student teacher. The supervisor files a report on the observation.

(Definition provided by Jennifer House, Coordinator, TESL Certificate Program, Vancouver Community College)

TEAL has opted for entry-level practica that attempt to document, in two independent reports, the effectiveness of the instructor in adult ESL teaching practice, reinforcing the concept that ESL is a distinct professional field.
There were three ways to gain this credit, initially, Options A, B, and C. After a period of grace, $C$ disappeared and $B$ will disappear, and new entrants to the profession will be required to meet the eventual minimum standard, Option A.

Other professions have sometimes grandfathered. For example, the School of Social Work at Dalhousie has a clause granting recognition for experience.

In part as a result of the policy of grandfathering, ATESL has been effective in achieving its goals. A large proportion of Alberta ESL teachers have gained accreditation and ATESL is functioning as a strong united pressure group influencing both federal and provincial funders. (For more detail, see below What Has Been the Outcome? and What is the Next Step?)

\section{Teaching Qualifications and the Practicum}

A specific supervised ESL practicum is not a requirement for ATESL.

Because of the variety of practicum requirements in Alberta and because there are not enough TESL courses at the universities to meet the demand, ATESL has not yet made any specific training demands. Evaluating the effectiveness of TESL practice teaching, a potentially divisive issue, has not been attempted.

"It is only when we, as a unified group, have stated our standards, that we can approach course programmers with suggestions or innovations." (ATESL Newsletter, September 1988)

According to David Wood of Mt. Royal College, Calgary, the TEAL form of supervised practicum does not really exist in Alberta:

- At the University of Alberta, the Diploma in Postsecondary Education with a Concentration in Teaching ESL, Department of Educational Policy Studies, does not appear to have a specific ESL practicum as a course offering. Students are encouraged to volunteer in an ESL program while taking the diploma. Similarly, the MEd program in Adult and Higher Education does not seem to include a practicum course. Presumably, 
The problem with this approach is that not all ESL training programs in $\mathrm{BC}$ incorporate this kind of practicum:

- The practicum specifically for ESL that is offered at Simon Fraser University in the Faculty of Education is offered through the Centre for Distance Education only and does not meet TEAL supervision requirements.

- The Post-Baccalaureate Diploma in Teaching English as a Second Language, offered jointly by Education and Linguistics, also falls in this category because it uses the same practicum.

- The Certificate Program in TESL Linguistics, offered in the Department of Linguistics at SFU, has its own practicum and TEAL recently acknowledged that this program meets the TESL training requirements for Level One certification.

As is the case in many other education faculties in Canada, ESL in the SFU Faculty of Education is just one of many subjects taught. It tends to be a specialization that is entered into after students have completed intensive practice teaching assignments. In many cases it only becomes a specialty at the postgraduate level because it is not recognized as a core subject by teachers' associations. Many education faculties in Canada believe that this system produces very welltrained, if not better trained, ESL teachers.

TEAL requests that teacher training programs adapt to TEAL requirements if its graduates wish to gain certification for adult noncredit ESL teaching, and SFU Education is not eligible for the certification process:

- TEAL does not receive many applications for certification from SFU. Those students who take the education ESL courses can be hired as ESL teachers for K-12

- SFU has not participated on the TEAL Institutional Standards Advisory Committee

- In Manitoba, a related issue led to suspension of the certification process. (For more information, see Accreditation in Other Provinces, Manitoba) these students completed practice teaching previously.

- At the University of Calgary, the Professional Diploma Programme in ESL, Department of Curriculum and Instruction, does have a specific practicum. The program is for practitioners, and requires one full practicum course that is offered in elementary, secondary or adult education. 


\section{Tiered Levels or a Level Minimum}

\section{Standard?}

The TEAL levels are graduated or tiered to recognize postcertification education, experience, and professional involvement and to provide incentives to attain these levels.

Candidates may apply at intervals for Level Three (Advanced) and Level Four (Master Teaching). Level Four requires a master's degree in a related field.

\section{Time Limits for Acquiring Experience}

BC-To be eligible for certification, full-time ESL teachers must gain 600 hours of experience in one year. Part-time ESL teachers must have a minimum of 300 hours over a period of three years.

Because of these time limits, teachers who remain in one city, or in one institution, in BC have an advantage in accumulating teaching hours. Those who teach in the north or overseas, where they may gain valuable cross-cultural and language learning experience, will face the attendant inevitable gaps in employment because of relocation.

A "special circumstance" for extending the period of time permitted to reach Level Two because of professional relocation could be employed as an equalizer.

For Levels 3 and 4 only full-time experience is mentioned in the requirements.

\section{Examples of ESL Teacher Training Programs Recognized for TEAL \\ Level One Certification}

TESL programs at the following $\mathrm{BC}$ institutions:

University of British Columbia

University of Victoria

Vancouver Community College

Simon Fraser University

(Certificate Program in TESL Linguistics, Department of Linguistics, appears to be accepted)

Also accepted:

Cambridge University-RSA CTEFL_A

(100-hour program)
Tiered Levels or a Level Minimum

\section{Standard?}

ATESL rejected the notion of a tiered system.

"The creation of a tiered system is not a viable option because tiering creates elitism within the TESL community without any commensurate benefit in public perception." (Accreditation of ESL Teachers in Alberta Committee Brief, November 1991)

There is only one eventual flat minimum standard rather than a series of levels or tiers.

\section{Time Limits for Acquiring Experience}

ATESL placed a time limit on the opportunity to grandfather into the profession, but no time limit is apparent for reaching 250 hours of classroom experience.

An indefinite time period was perhaps most useful considering the 1220 hours of experience required for Option $C$.

The new entry level that is being considered for trained but inexperienced teachers would be more rigorous if some time limit were imposed to ensure that training is applied relatively soon after qualifications are acquired.

\section{Examples of ESL Programs Recognized for ATESL Accreditation}

TESL Programs at the following Alberta institutions:

University of Alberta

University of Calgary

Also accepted:

Cambridge University—RSA DipTEFLA

(1 year program)

Cambridge University-RSA CTEFLA

(100 hour program) is accepted for Option

$B$ only. (Source: Veronica Baig, Accreditation Board) 
Other non-BC programs are currently being reviewed.
Accepted on an individual basis:

University of Saskatchewan-CERTESL is not automatically accepted now because it is noncredit and an undergraduate degree is not required for it. With a degree plus the CERTESL, each case will be considered individually. (Source: Silvia Begin, Past President, ATESL)

\section{Procedures for Certification/Accreditation}

\section{Procedures for TEAL Certification \\ "All applications will be reviewed by the BC TEAL Professional Standards Certification Board (PSCRB) which consists of three ESL professionals appointed by the TEAL Execu- tive." (Procedures for Certification, BC TEAL Professional Certification Service)}

This Board is composed of three TEAL members who ideally represent a variety of public and private adult ESL institutions. Members normally serve for two years. One board member serves for three years for continuity. The chairs of TEAL committees are Executive members, who submit nominations to the committee for Executive approval. Institutions/groups may recommend candidates. The Professional Standards Advisory Committee (PSAC), a six-member subcommittee of PSCRB, meets to consider special cases that are problematical, to review and establish criteria for professional certification, and to address ongoing issues. Committee members must be TEAL members with an interest in teacher training and professional development issues.

The PSCRB makes recommendations to the PSAC about areas requiring review/change/updating.

The Certification Board meets twice a year in November and May and decisions are to be made within a month. A fee is charged for applications.

\section{Appeals}

Appeals are made first to PSAC and then to the Executive. If PSAC cannot reach a decision, the TEAL Executive will make a final ruling.

\section{Procedures for ATESL Accreditation}

The Accreditation Board has complete authority to make decisions based on submitted applications and in concert with the guidelines for accreditation. The Board operates at arm's length from the ATESL Board, which would only be involved in unusual circumstances. The Board and ATESL exchange representatives to ensure communication.

All appointments to the three-member Board are for two years except in the first year when there would be three-year, two-year and oneyear terms. Appointments to the Board are subject to approval at an annual general meeting of ATESL. The Accreditation Board can make recommendations for changes in their annual report to ATESL.

The Accreditation Board meets twice a year. (Accreditation of ESL Teachers in Alberta, 1992)

\section{Appeals}

Candidates who feel their applications have been rejected unfairly have recourse to an appeal procedure. Transcripts and certificates are required, but may be copies unless a dispute necessitates originals. If people are turned down it is usually because they do not have classroom experience or because of some minor problem with the form, according to Veronica Baig of the Accreditation Board.

The appeal is made directly to the ATESI Board in the form of a letter outlining the candidate's case. The Board discusses the appeal and makes a decision, by voting if necessary. 


\section{Conclusions}

Accountability to the Membership

Because the Executive appoints, or approves the appointment of Certification Board and Committee Members, the procedures and amendments could be strongly influenced by the Executive, which is, of course, elected by members.

Certification procedures and changes to them, consistent with TEAL's desire to set and maintain professional standards, do not require direct ratification by the membership.

\section{Documentation of Claims}

Documentation of all claims is taken seriously and a number of detailed forms are provided to guide this process, which include teaching reports and reference reports to verify the quality of all claimed experience. If applicants are turned away, it is often with instructions to obtain more documentation, according to Certification Board Chair, Patricia Watson.

Such documentation could be time-consuming and difficult to amass, especially for teachers who have taught in different cities and countries over an extended time.

TEAL procedures address the issue of qualify control and document thoroughly and officially all requirements for certification.

\section{Conclusions}

Accountability to the Membership

The required approval of Board appointees by membership at the annual general meeting, and the annual report to ATESL, ensure that the Board is directly accountable to the membership. ATESL's commitment to a democratic process also applies to the procedures for accreditation.

\section{Documentation of Claims}

Transcripts, certificates, and documentation of classroom time (contact names) are required, but documentation is not routinely verified unless a dispute arises. However, a number of applicants are asked on a random basis to provide documentation of teaching hours and employment to help ensure the validity of the process. Letters or reports attesting to effectiveness are not required.

A criticism of this approach, which assumes professionalism on the part of the teacher, is that there is no specific quality control mechanism. 


\section{What has been the Outcome of Certification/Accreditation?}

\section{Certification Statistics}

800 Number of adult ESL TEAL members

160 Number of teachers who have gained certification

175 Number of teachers who have applied for certification

(1994 estimates given by BC TEAL. TEAL membership not mandatory for certification.)

$20 \%$ of adult ESL teachers have become certified

BC TEAL chose not to grandfather. TEAL also chose to set entry level standards that do not necessarily reflect actual teacher qualifications and training programs, but rather set a standard that would enhance teacher credentials. In consequence, the group of teachers with TEAL certification is somewhat limited in representation of the total adult ESL teaching body.

\section{Organizations that now Request TEAL} Certification for Teachers

No survey has been done in $\mathrm{BC}$, but the following ESL teaching schools do require it, according to various sources listed at the end of the report:

- Vancouver Community Colleges

- Pacific English Language Schools Association-Seven international schools whose regulations require that all teachers in these schools have TEAL Certification.

Whether LINC programs require it or not was not clear to me. Some programs may ask what TEAL levels are but do not necessarily require it.

It is perhaps somewhat difficult for $B C$ teaching institutions to require TEAL certification, as so many teachers do not have it.
Accreditation Statistics

600 Number of ATESL members

300 Number of teachers accredited. (Very few applications have been turned down.)

(These statistics are estimates given by the ATESL Accreditation Board.)

$50 \%$ of ATESL members are accredited.

ATESL accreditation has been gained by a large proportion of the members of ATESL due to grandfathering and because all Alberta TESL training is accepted provided enough hours are accumulated. The result reflects Alberta's inclusive model and wish to unite to influence employers and funders.

Organizations that Require Accreditation for Teachers

No survey has been done in Alberta. This information was gathered from various Alberta sources listed at the end of the report:

- Provincial Vocational Schools and Colleges

- Mt. Royal College

- Maple Leaf Academy, Calgary

- Connections Canada Inc., Edmonton

English Language Professionals, Edmonton 


\section{Impact on ESL Teacher Training}

Programs

All Simon Fraser University ESL programs now have either a placement or a practicum whereas before certification they did not all have one, according to Kelleen Toohey, Associate Professor, SFU.

\section{Impact on Standards for}

\section{ESL Program Delivery}

BC TEAL has taken the work of setting standards one step further, to the ESL program provider level.

The Institutional Standards Advisory Committee was formed by TEAL to recommend standards for ESL programs in British Columbia. This committee represents a cross-section of ESL institutions including the English Language Institute at UBC, Vancouver Community College, the YMCA Language Institute, and at least five private language institutes. SFU is not taking part.

The Committee has published a Document of Recommended Standards for British Columbia ESL Institutions. The TEAL Professional Certification Levels are required for instructors, and Level $I$ is recommended as a minimum in this document.
Impact on ESL Teacher Training Programs

ATESL has not required any changes to existing programs.

Plans are underway at the University of Alberta to offer a diploma in TESL in the Department of Educational Psychology. This program will offer more courses that are directly relevant to TESL than previously available. $^{1}$

\section{Impact on Standards for}

ESL Program Delivery

ATESL expanded the work begun in the accreditation initiative by lobbying the provincial government to establish minimum program standards for LINC and other ESL programs. This reflects ATESL's original rationale and goal to influence funders and employers.

In 1994 ATESL was contracted by Advanced Education and Career Development, Province of Alberta, and by Citizenship and Immigration, Government of Canada, to build on recommended standards established in 1993 by Alberta Career Development and Employment.

The Best Practice Guidelines for Adult ESL/LINC Programming and Instruction In Alberta were drafted in April 1994. These guidelines were developed using focus groups and conference calls to ensure a consensus among all program providers in the province. The Best Practice Guidelines, if adopted, will assist funders to assess applications for LINC programs.

The ATESL accreditation guidelines are the definition of ESL professionalism adopted in the Best Practice Guidelines.

Editor's Note: The TESL diploma in the Department of Educational Psychology was instituted in the fall of 1995. 


\section{What is the Next Step for British Columbia and Alberta?}

\section{$B C T E A L$}

The TEAL certification and institutional standards could well influence private language centers across Canada. A working group of private center representatives from across Canada,

has been engaged in discussions regarding the establishment of a national association of private ESL centers, one of the main functions of which would be the establishment and maintenance of industry quality standards.

In this respect, they have been working with the Document of Recommended Standards for British Columbia ESL Institutions developed by the BC TEAL group. The BC TEAL framework addresses the issue of teacher certification and these standards have been accepted in principle by the association's prospective membership." Craig Riggs, Marketing Manager, International Language Institute, Halifax.

The TEAL Certification Board is now in the process of deciding which out-of-province ESL training they accept for certification and how these programs fit into the requirements (Patricia Watson, Chair, Certification Board, TEAL).

Through articulating certification and institutional standards, TEAL is influencing the standards of employers and program providers, and TEAL standards may be adopted by private institutions across Canada.

\section{Alberta TESL}

The Best Practice Guidelines are awaiting acceptance or modification by the governments involved.

The ATESL accreditation guidelines are the definition of ESL professionalism adopted in the Best Practice Guidelines. Acceptance of the Best Practice Guidelines will, as a result, imply acceptance of the ATESL accreditation of ESL teachers by Alberta Advanced Education, and Canada Citizenship and Immigration. The ATESL process may impact national standards eventually.

Another issue ATESL may address is the fact that there are limited resources at the universities to meet the demand for TESL courses.

Although ATESL has not yet dealt with some professional issues such as how to assess teaching success, the ATESL potential impact on government and national standards through the Best Practice Guidelines could be very great. How much of this political impact derives from the inclusive, unifying, consensus ATESL approach?

\section{Accreditation in Other Provinces}

\section{Accreditation in Saskatchewan}

\section{What were the Rationale and Goals for Accreditation?}

The Saskatchewan TESL organization, SCENES, adapted their rationale for accreditation from the ATESL model. Different circumstances with regard to the availability of training programs in the province led to a different process, which is, however, philosophically in keeping with the Alberta model of consensus and inclusion.

\section{Why do we Need Accreditation?}

1. A statement of standards, as defined by the peer group, makes the ESL profession a unified community of teachers who possess equivalent backgrounds. 
2. The statement of standards provides a tool for self-evaluation and quality control within the profession.

3. As an accredited body the ESL teachers have more credibility and are in a better position to lobby with the governments for changes in policy.

4. The standards we agree on give direction to professional development opportunities needed in Saskatchewan.

5. Last but not least, this accreditation of professionals by a professional organization will be an important step toward accreditation by the Department of Education.

(From a SCENES letter accompanying a questionnaire for the membership.

SCENES adapted this rationale from the ATESL newsletter of September 1988).

The SCENES goal of eventually gaining accreditation from the Department of Education was not a stated goal for ATESL. However, ATESL is on the verge of gaining recognition for their minimum standard for accreditation from Advanced Education and Career Development in Alberta.

\section{Definition}

"In this discussion, the term accreditation means a formal statement of minimum but essential standards based on education, experience, and professionalism which has the support of the TESL community." (From the SCENES letter accompanying the membership questionnaire).

What is the Accreditation Process?

1. In a letter accompanying a membership questionnaire, accreditation was defined and reasons for it were set out. This was done at the executive level.

2. SCENES wished to have the ESL teachers define the standards. Permission to use the ATESL questionnaire was granted. The ATESL questionnaire was then mailed to SCENES members to gain a profile of ESL teachers in Saskatchewan and an indication of which academic courses and experience they considered important, of how to measure experience, and of what qualifications they needed or would like to obtain. The findings were reported in the next SCENES newsletter.

3. Results indicated that $48 \%$ of SCENES members believed strongly that education and experience were of equal importance. SCENES members stressed the lack of specific kinds of TESL professional courses in the province at that time. Some ESL courses were available in the BEd program. SCENES decided that, until a specific TESL program was available, defining accreditation standards would be difficult.

4. Based on the questionnaire results, in 1992 the Certificate Program in Teaching English as a Second Language (CERTESL) began in the Extension Division of the University of Saskatchewan. The courses included TESL methodology and theory courses, curriculum and program design, evaluation, and a supervised practicum.

All of the CERTESL courses except for the three-week summer practicum are distance education courses, to provide opportunities for teachers in the North or in 
rural areas. The practicum is an on-campus supervised practicum. However, a distance supervised practicum or a professional project can be used to fulfil this requirement. Other courses in the program also require access to ESL learners. All courses are noncredit, but practica or professional projects are marked pass / fail. Three hundred people registered in the program, including students from other parts of Canada.

5. Admission requirements are grade 12 or equivalent. (60\% of SCENES members had a degree according to the questionnaire results.)

What is the Next Step for Saskatchewan?

SCENES can now request professional training for accreditation because it is offered. SCENES has asked to have their certificate accepted automatically for ATESL accreditation. Currently, ATESL accredits CERTESL graduates on a case-by-case basis, because an undergraduate degree is an ATESL requirement.

\section{Certification in Manitoba}

What was the Process for Achieving Certification?

Manitoba began one of the early initiatives in standards and recognition for ESL teachers but the initiative has not yet borne fruit and is not being actively pursued at present. The most informative aspect of the Manitoba case is where and how the process foundered.

1. In 1985 a committee was set up to look at certification. The committee represented all of the adult ESL teacher training and providing organizations in the province including the Settlement and Adult Language Training (SALT) branch of the Department of Education, the universities, community colleges and the Winnipeg \#1 School Board.

Interestingly, the Department of Education was involved from the beginning. No other certification/accreditation process in Canada was initiated with government involvement. TESL Ontario also has the intention of including government involvement from the beginning.

2. Principles of certification (which I have so far not been able to locate) were drafted and the Manitoba committee decided that their first goal or initiative would be to address the issue of the specific training for adult ESL teachers in the province. A Post-Baccalaureate ESL specialty in education at the University of Manitoba existed, but a certificate or courses specifically for noncredit adult ESL was not offered.

3. The Manitoba committee began to develop a 10-course part-time adult ESL certificate. The first course was offered twice. Consultation and participation of employers and teachers was to be used to develop the certificate, and the practicum was to be worth $50 \%$. It was to be similar to the Cambridge University RSA approach, but with a settlement focus. 
How the Process Foundered: The University/Non-University ESL Teacher

Training Issue

The process foundered over university versus nonuniversity adult ESL training, a related issue to this that caused divisions in British Columbia. (See first section, University vs. Non-University ESL Teacher Training, Teacher Qualifications and the Practicum.)

The University of Manitoba held that the certificate should be offered through the Faculty of Education as with other teacher training and that the Post-Baccalaureate model would be useful. SALT branch of the Department of Education and others did not believe the university was necessarily the only repository of expertise on adult ESL.

A great deal of the Winnipeg noncredit adult ESL teaching to immigrants is done through the Winnipeg school boards and all those teachers are qualified through the Faculty of Education.

As a result of the complexities of the situation and the strength of the Faculty of Education in ESL in Manitoba, the new certificate was not pursued by the Department of Education and the committee. The issue of who would offer the certificate was never resolved.

The entire certification process stopped at this point.

What is the Next Step for Manitoba?

At the present time, Providence College, a small private college, has an adult TESL program, and Red River Community College offers an Adult Education Certificate. The University of Manitoba offers a Post-Baccalaureate specialty.

In 1992 the idea that ESL teachers' organizations should decide on certification requirements arose, but ultimately major adult ESL providers like the Winnipeg school boards, with BEd teachers, and Red River Community College, with its unique collective agreements, must be taken into account.

\section{Conclusion}

Although the process began early in Manitoba, and inspired ATESL's initiative, it foundered because of differences of opinion about the appropriate training for noncredit adult ESL. Because so much adult ESL is done within the school boards in Manitoba, it seems likely that a consensus model that accepts both BEd ESL training and experience, and other specific TESL certificates offered in the province, more like the Alberta model, would be a way to initially resolve differences. Lack of acceptance of some BEd ESL training in British Columbia continues to be a source of unresolved tension there.

\section{Certification in Ontario}

Why is Certification Being Pursued?

Ontario is in the unique situation of being home to a number of certificate and diploma courses for noncredit adult ESL. These courses are not regulated as to 
content, length, or administrative requirements. LINC funding assumes that teachers are equally qualified, but there is disparity in qualifications and salaries.

Employers and funders have contacted TESL Ontario wanting to know what the different TESL qualifications mean. Teachers want recommendations on which TESL programs to take. TESL Ontario needs answers for these questions according to Razika Sanaoui, Chair, Issues and Research, TESL Ontario.

\section{What are the Goals for the Ontario Process?}

Ontario's goal is to use an inclusive process with input from all of the possible involved parties. Surveys and focus groups will inform a committee, which will develop a definition and process for certification.

The project will be conducted in three phases:

1. the qualifications of instructors teaching noncredit adult ESL courses in Ontario will be surveyed first;

2. teacher-training programs that issue ESL teaching certificates across the province will be surveyed next;

3. the objectives of phase three of the project are to (a) develop and (b) to validate a protocol and standards for the certification of instructors who teach ESL to adults in noncredit courses in Ontario. Focus groups, informed by the results of surveys conducted in previous phases of the research and organized to represent various stakeholders in and outside the ESL community, will examine all the issues, consider certification standards and protocols in other provinces and in other parts of the world, formulate a set of principles to guide the development and administration of a protocol and standards for certification, and establish a steering committee.

The steering committee will then develop a protocol and standards for certification conforming to the guiding principles generated by the focus groups.

A sample of ESL instructors from the initial survey will provide feedback on the certification protocol that will help redefine the certification protocol and standards before implementation. There will also be a two-year monitoring of the effectiveness after implementation.

(Adapted from Establishing Standards and a Protocol for the Certification of Adult ESL Instructors in Ontario, TESL Ontario.)

\section{Initial Government Involvement in the Process}

"Funding for the project will be sought from relevant branches of the Provincial and Federal governments" (Establishing Standards and a Protocol for the Certification of Adult ESL Instructors in Ontario, TESL Ontario).

Interestingly, TESL Ontario has the goal of including the provincial Education and Training ministry and the federal Citizenship and Immigration Ministry from the beginning to ensure that the process and the final certification protocol will be approved and recognized. 


\section{Conclusions}

The Ontario process will attempt to be extremely inclusive and thorough, including all involved parties in the province, over and above TESL Ontario members. A final ratifying vote, similar to ATESL's, is not included, but the process remains to be defined by the profession.

No other provincial ESL organization has successfully attempted to include provincial and federal governments in the initial definition of certification/accreditation. The Manitoba effort to satisfy government and university and other adult ESL groups from the beginning of the process contributed to the failure to proceed with certification. ATESL and TEAL have both succeeded by developing protocols within the professional organization and then seeking recognition, based on the established protocols.

In January 1995, TESL Ontario's certification project received some funding from the Ontario Ministry of Education.

TESL Ontario is awaiting further government funding in order to proceed with this most inclusive and thorough of certification processes.

\section{Quebec}

SPEAQ is no longer part of TESL Canada. Most ESL teaching is done in the school system by completely bilingual teachers who must also speak French to communicate with the administration. Concordia and McGill train many ESL teachers for the public school systems.

Private language schools teach francophone adults. Adult ESL for immigrants is mostly done on a volunteer basis at community centers. Immigrants learn French on arrival in Quebec. No indication has been received that SPEAQ is pursuing the issue of noncredit Adult ESL certification. Noncredit adult French instruction would be a more pressing issue in Quebec.

\section{Prince Edward Island}

There is no special movement toward accreditation in PEI yet. Most adult ESL in the province is private sector and community college LINC training.

\section{New Brunswick}

The 20 members of NB TESL have no opportunity to study ESL in the province other than through Adult Education at the University of New Brunswick.

Teachers are moving to upgrade their qualifications: three are enrolled in the Saskatchewan CERTESL program; others have attended the summer course at St. Mary's University in Halifax.

Berth Vye is researching accreditation for TESL New Brunswick.

\section{Newfoundland}

The ESL program is extremely small and no evidence was obtained of movement toward accreditation. 


\section{References}

Accreditation Committee of Alberta Teachers of English as a Second Language (ATESL). (1991). Accreditation of ESL teachers in Alberta committee brief. Edmonton: Author.

Alberta Teachers of English as a Second Language (ATESL). (1992). Accreditation of ESL teachers in Alberta. Edmonton: Author.

Alberta Teachers of English as a Second Language (ATESL). (1994). Best practice guidelines for adult ESL/LINC programming and instruction in Alberta (draft). Edmonton: Advanced Education and Career Development, Government of Alberta and Citizenship and Immigration, Government of Canada.

Association of BC Teachers of English as an Additional Language (BC TEAL). (1994). BC TEAL certification service and standards for professional certification. Burnaby, BC: Author.

Association of BC Teachers of English as an Additional Language (BC TEAL). (1994). Institutional Standards Advisory Committee. Document of recommended standards for British Columbia ESL institutions. Burnaby, BC: Author.

Association of BC Teachers of English as an Additional Language (BC TEAL) Professional Standards Committee. (1987). Professional standards committee report. Burnaby, BC: Author.

Association of Teachers of English as a Second Language in Ontario (TESL Ontario). (1994). Establishing standards and a protocol for the certification of adult ESL instructors in Ontario. Toronto, ON: Author.

Continuing Education, Vancouver Community College. (1994). Teaching English as a second language program information guide. Vancouver, BC: Author.

Department of Adult, Career and Technology Education, University of Alberta. (1993). Diploma in postsecondary education, concentration in TESL. Edmonton, AB: Author.

Department of Curriculum and Instruction, University of Calgary. (1994). ESL diploma programme. Calgary: Author.

Department of Linguistics and Faculty of Education, Simon Fraser University. (1994). Post-Baccalaureate Diploma in Teaching English as a Second Language. Burnaby, BC: Author.

Department of Linguistics, Simon Fraser University. (1994). Certificate Program in TESL Linguistics. Burnaby, BC: Author.

Department of Educational Policy Studies, University of Alberta. (1993). Master of education program in adult and higher education course descriptions. Edmonton, AB: Author.

Extension Division, University of Saskatchewan. (1994). Certificate program in teaching English as a second language registration handbook. Saskatoon, SK: Author.

Faculty of Education, Simon Fraser University. (1994). Undergraduate courses-Education. Burnaby, BC: Author. 